\section{(2) OPEN ACCESS}

\title{
High physical work demands and working life expectancy in Denmark
}

\author{
Jacob Pedersen (ㄱ), ${ }^{1}$ Bastian Bygvraa Schultz, ${ }^{1}$ Ida E H Madsen ํㅣ, \\ Svetlana Solovieva, ${ }^{2}$ Lars L Andersen (1) ${ }^{1}$
}

\begin{abstract}
- Additional material is published online only. To view please visit the journal online (http://dx.doi.org/10.1136/ oemed-2019-106359).

${ }^{1}$ National Research Centre for the Working Environment, Copenhagen, Denmark ${ }^{2}$ Finnish Institute of Occupational Health, Helsinki, Finland
\end{abstract}

Correspondence to Dr Jacob Pedersen, National Research Centre for the Working Environment, Copenhagen, Denmark; jpe@nfa.dk

Received 10 December 2019 Revised 11 March 2020 Accepted 14 March 2020 Published Online First 12 May 2020

\section{Check for updates}

(C) Author(s) (or their employer(s)) 2020. Re-use permitted under CC BY-NC. No commercial re-use. See rights and permissions. Published by BMJ.

To cite: Pedersen J,

Schultz BB, Madsen IEH,

et al. Occup Environ Med

2020:77:576-582.

\section{ABSTRACT}

Objective In most European countries, political reforms gradually increase the statutory retirement age to counter the economic costs of a growing elderly population. However, working to a high age may be difficult for people with hard physical labour. We aim to study the impact of high physical work demands on working life expectancy (WLE).

Methods We combined physical work demands assessed by job exposure matrix (JEM) and longitudinal high-quality national registers (outcome) in 1.6 million Danish workers to estimate WLE and years of sickness absence, unemployment and disability pension. The JEM value for physical work demand is a summarised score of eight ergonomic exposures for 317 occupations groups, sex and age. The WLE was estimated using a multistate proportional hazards model in a 4-year follow-up period. Results Individuals with high physical work demands had a significantly lower WLE, than those with low physical work demands, with largest differences seen among women. At age 30 years, women with high physical work demands can expect 3.1 years less working, 11 months more of sickness absence and 16 months more of unemployment than low-exposed women. For 30-year-old men, the corresponding results were 2.0 years, 12 months and 8 months, respectively. Conclusion Our findings show that high physical work demands are a marked risk factor for a shortened working life and increased years of sickness absence and unemployment. The results are important when selecting high-risk occupations, and expand the knowledge base for informed political decision making concerning statutory retirement age.

\section{INTRODUCTION}

The increasing life span and declining birth rates are transforming the age distribution in Europe towards a growing elderly population above the statutory retirement age. ${ }^{1}$ This has led to increases in retirement age based on the assumption that longer life span equals proportionally better health and workability. In Denmark, the statutory retirement age is set to increase from $65 \frac{1}{2}$ years in 2019 to 72 years in $2050 .^{2}$ The intention of these regulations is that an average person should have $14 \frac{1}{2} 2$ living years after retirement. However, such assumptions are not without challenges. First, healthy life expectancy is not increasing at the same rate as life expectancy, in part due to modern medical treatments, leading to increased survival of elderly individuals with life-threatening disease. ${ }^{3}$ Second,

\section{Key messages}

What is already known about this subject?

- Physical work demands are strongly associated with long-term sickness absence and disability retirement.

- Job exposure matrices provide mean occupational exposure and therefore have a high utility for large register studies.

- Working life expectancy (WLE) is a useful measure to inform preventive policies and practices.

\section{What are the new findings?}

- Applying a multistate framework with a life course perspective, we showed that high physical work demands markedly reduces the WLE.

- Male and female employees in occupations with high physical demands spend substantially more time in sickness absence and unemployment compared with employees in occupations with low physical work demands.

\section{How might this impact on policy or clinical practice in the foreseeable future? \\ - Considering the expected increase in statutory retirement age in many European countries, the findings emphasise the urgency of addressing problems in high-risk occupations.}

due to socioeconomic inequalities in health, not all groups in society will live to the same age nor have the same number of healthy life years after retirement. ${ }^{4-6}$ Third-and the primary focus of the present study-these reforms may not account for the ageing process in occupations with hard physical labour. For example, from the age of 40 years muscle strength declines 1\%-2\% per year, making physical labour increasingly more difficult as age progresses. ${ }^{7}$ Indeed, numerous prospective studies have documented the negative impact of physically heavy work on health, workability, and risk of sickness absence and early retirement. ${ }^{8-15}$

Most of previous studies on health, workability and labour market affiliation, however, use a single end point as outcome-for example, transitioning from employment to disability retirement-without considering the many possible transitions occurring during working life, for example, from employment to unemployment, from employment to sickness 
absence, and back to work. Consequently, little is known about the impact of physically heavy work on workability during working life course.

Working life expectancy (WLE) is one summary measure of health and labour market affiliation in the working population. ${ }^{16-26}$ WLE, as analogue of life expectancy, expresses the number of years a person at a given age is expected to be at work until retirement from the labour market. In the present study we additionally estimate the number of years a person is expected to be in unemployment, sickness absence and early retirement due to disability pension. The WLE measure is easily converted into to working years lost (WYL), a useful indicator in evaluating long-term consequences of changes in retirement legislations. Likewise, WYL may show interesting changes in the expected duration of unemployment, sickness absence, disability pension and the risk of early death.

The aim of the present study is to explore the impact of high physical work demands on WLE in Denmark. The analysis of WLE combines information on labour market transitions from high-quality national registers and information on physical work demands based on a job exposure matrix (JEM).

\section{METHOD}

\section{Jurisdictional context: the Danish labour market}

The Danish labour market is characterised by a flexicurity system with high labour market participation rates $75 \%$ for the first quarter of 2019), ${ }^{27}$ low formal employment protection, generous and accessible social benefits, and a high turnover of the workforce. ${ }^{28}$ The Danish system contains both insurance and non-insurance unemployment benefits and a sickness absence benefit that compensate the employer from the 30th day of sick listing. Additionally, the Danish system includes early retirement schemes of which the disability retirement pension is the only one accessible for all. For a start, a disabled individual can be approved for either the full or the gradual disability retirement pension. The official retirement age in Denmark concerning the follow-up period of the study is 65 years of age.

\section{Study design}

The source population of this longitudinal study was provided by Statistics Denmark, and includes all Danes between the ages of 18 years and 65 years with a primary occupation ultimo November 2013 ( $n=2162$ 390, 49\% women). The sample included information on occupation, sex and date of birth. The occupations were coded in the Danish Classification of Occupations format, which corresponds to the International Classification of Occupations. The sample was linked with the Danish Register for Evaluation of Marginalisation (DREAM), which contains weekly registrations of all major social benefits payments in the period from 1 January 2014 until 31 December 2017. ${ }^{29}$ Information on date of death was taken from the Danish death register, if applicable. All data were provided on an individual level with an encrypted person's identification number.

\section{Exposure}

The individual exposure values of physical work demand were provided by linking a JEM to the study population by their age, sex and occupation code. The JEM was made using the Danish Work Environment and Health study 2012 and has been described by Madsen et al. ${ }^{30}$

The JEM values on the physical work demand, ranging between 8 and 48, were estimated by regression analysis. The exposure values correspond to a summary index, constructed

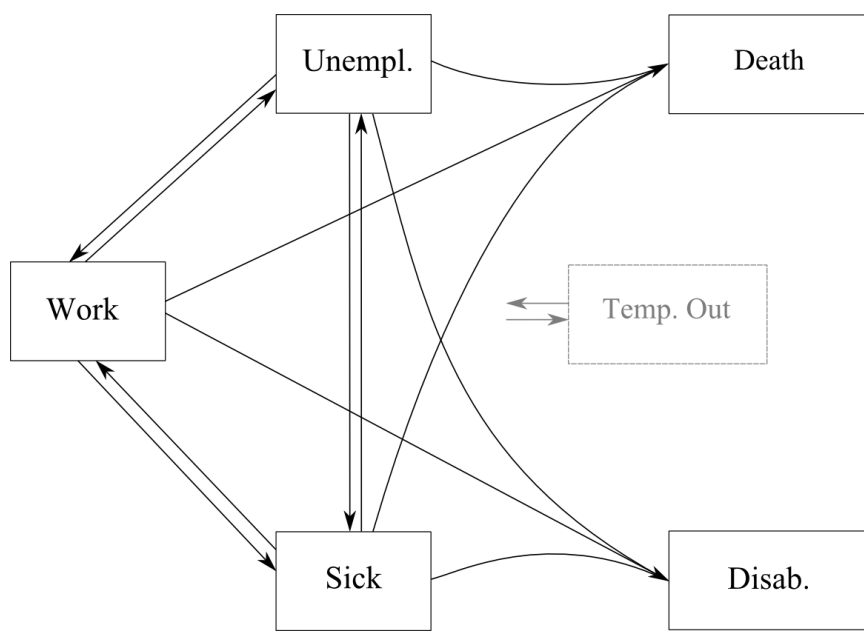

Figure 1 The multistate model with the six states: work, sickness absence, unemployment, disability retirement pension (disability), temporary exclusion from the labour market (temporary out), and death. The transitions are represented as arrows (adapted from Pedersen and Bjorner [19]).

from eight specific physical workload exposures, scored from 1 (never) to 6 (almost all the time). Thus, an increasing score indicates increasing physical work demands. A detailed description of the specific physical workload exposures is in the online supplementary material.

To increase the exposure contrast we divided the sample into three groups according to the exposure values: lower than 16 (low physical work demands), 16 or between 16 and 28 (medium physical demands), and 28 or higher (high physical demands). Because the exposure contains specific exposures that are opposing-for example, an item on standing and one on siting-it is unfeasible to gain a score of 4 and above consistently on each item. Therefore, the limit for high physical work demands was set to 28 .

The online supplementary tables $1-3$ show the top 10 male and female most frequent occupations, for the high-exposed, medium-exposed and low-exposed groups, respectively. The male occupations in the high exposure group include construction and general manual labour such as carpentry, masonry, painting and plumbing. The female occupations with the high physical work demands are related to cleaning labour and manufacturing industries.

\section{Labour market affiliation}

The labour market affiliation was measured according to the multistate model shown in figure 1 , with boxes illustrating the labour market states and arrows showing the possible transitions. The model contains four recurrent labour market states: (1) Work-when not receiving social payments. (2) Unemployment-when receiving unemployment benefit and being available for immediate labour. (3) Sickness absence-when receiving sickness absence benefits. (4) Temporarily out of the labour market-when on a leave for example, maternity leave, receiving education benefits or emigrated. The model additionally contains two absorbing states: (1) Disability Retirement Pension-when on disability retirement benefits due to limited or no workability. (2) Death. We based all six states on the records from the DREAM register and the Danish death register. 


\section{Statistical analyses}

We used a multistate model (figure 1) when analysing the transition probabilities between the six labour market states using age as the underlying time axis (30-65 years) in the follow-up period from 1 January 2014 to 31 December 2017. Individuals enter the model by left truncation either at the age at the start of the follow-up period or during the follow-up period from the date of turning 30 years. A person exits the model by right censoring when the person turns 65 years, or at the end of the follow-up period, whichever comes first.

We followed the procedure introduced by Pedersen and Bjorner to estimate the WLE, using long formatted data and age as time axis. ${ }^{19}$ We estimated an instantaneous transition matrix for each age by the hundredths. We estimated the matrices by sex and for the low exposed. We used the Chapman-Kolmogorov equation to gain transition-specific baseline hazards and the state occupation probabilities. To gain the instantaneous transition matrix of the highly exposed we adjusted the matrices of the low exposed with estimates from a Cox proportional hazard regression, using the low exposed as the reference group. During Cox regression we collapsed the transitions to the temporary out state to ensure a sufficient number of transitions to the state at all ages. This was also done for the disability pension and death states.

We estimated the WLE as the expected duration of time in the work state given by the combined area under the state probability and the incoming transition probabilities curves. We estimated the expected time in the unemployment, the sickness absence, and the disability states using the same approach. ${ }^{31} \mathrm{We}$ additionally restricted our results to individuals who, during the follow-up period,were 30 years and older. This is because the results for individuals younger than 30 years are in general more uncertain, due to more frequent periods of education and maternity leave. We calculated 95\% CIs using the Greenwood variance. All analyses were made in SAS V.9.4 by custom-made code and the PHREG procedure.

\section{RESULTS}

To limit the number and size of the tables, we show only the results for women and men aged 30 years, 40 years and 50 years. Additionally, we focus on the results comparing the high exposed to the low exposed.

More men than women were classified as having high physical work demands during the follow-up period (table 1). The men with high exposure were on average 2.8 years younger than the low-exposed men, while the high-exposed women were 0.8 years older than the low-exposed women.

In both sexes, individuals with high physical work demands were expected to spend significantly less time working and more time in unemployment, receiving sickness absence benefit or disability pension than the low exposed (figure 2). In both sexes and at all ages, the absolute numbers of figure 2 show that WLE was decreasing with increasing physical work demands (table 2). In contrast, expected time in other states was linearly associated with physical work demands. At the age of 30 years, the expected time at work was 31.9 years among high-exposed men and 33.9 years among low-exposed men. For women, the corresponding numbers were 29.6 years and 32.7 years, respectively. Furthermore, a 30-year-old man with high exposure was expected to have 1.5 years (18 months) of sickness absence and 1.1 years (13 months) of unemployment, while a low-exposed man was expected to have 0.4 years of sickness absence and 0.4 years (5 months) of unemployment. The corresponding results for women were 1.9 years of sickness absence and 1.9 years (23 months) of unemployment for the high exposed, while 1 year of sickness absence and 0.6 years ( 7 months) of unemployment for the low exposed.

The reduction in WLE (WYL) for women with high physical work demands was statistically significantly larger at the age of 30 years and tended to be larger at other ages than the comparable loss for men (table 3 and online supplementary figure 1). The first column of table 3 shows that a 30 -year-old woman exposed to high physical work demands is expected to be 3.1 years less at work than a woman exposed to low physical work demands. The comparable difference for a 30-year-old man was 2.0 years. In addition, a 30-year-old woman with high exposure was expected to spend 0.9 years (11 months) more on sickness absence and 1.3 years (16 months) more in unemployment, compared with a similarly aged and low-exposed woman. For a 30-year-old man, the difference between high-exposed and low-exposed groups in expected number of years was 1.0 more year for sickness absence and 0.7 additional year ( 8 months) for unemployment.

In addition, table 3 shows that a 30-year-old high-exposed woman was expected to have 0.6 year $(7$ month) more of disability pension than a 30 -year-old low-exposed woman, while the difference for a 30-year-old man was 0.1 year (approximately 1 month). The differences for the temporary out state and death state were non-significant based on the 95\% CIs.

\section{DISCUSSION}

We used a nationwide register-based data set and a recently developed JEM to quantify the impact of high physical work demands on WLE and loss of working years in the Danish working population. We found that in both sexes from the age of 30-65 years, the WLE is inversely associated with physical work demands. In contrast, the expected sickness absence time and unemployment time are positively associated with physical

\begin{tabular}{|c|c|c|c|c|c|c|}
\hline Sex & $\begin{array}{l}\text { Physical } \\
\text { demands }\end{array}$ & N (\%) & Mean age (STD) & Aged 30 years $N(\%)$ & Aged 40 years $N(\%)$ & Aged 50 years $N(\%)$ \\
\hline \multirow[t]{4}{*}{ Men } & Low & 305527 (37.4) & $45.1(9.2)$ & $11969(26.8)$ & $52079(41.1)$ & $52022(37.2)$ \\
\hline & Mid & $475102(58.2)$ & $44.8(9.4)$ & $27826(62.2)$ & 71891 (56.4) & $80964(57.9)$ \\
\hline & High & $35920(4.4)$ & $42.3(9.6)$ & $4935(11.0)$ & $3193(2.5)$ & $6933(5.0)$ \\
\hline & Total & 816549 & $44.8(9.3)$ & 44730 & 127506 & 139919 \\
\hline \multirow[t]{4}{*}{ Women } & Low & $310301(38.0)$ & $44.3(9.1)$ & $18150(35.0)$ & $52079(41.8)$ & $54167(39.3)$ \\
\hline & Mid & $460010(57.8)$ & $44.6(9.3)$ & $32072(61.8)$ & 70814 (56.9) & $78411(56.8)$ \\
\hline & High & $25842(3.2)$ & $45.1(8.5)$ & $1637(3.2)$ & 1640 (1.3) & $5422(3.9)$ \\
\hline & Total & 796153 & $44.3(9.1)$ & 51859 & 124533 & 138000 \\
\hline
\end{tabular}



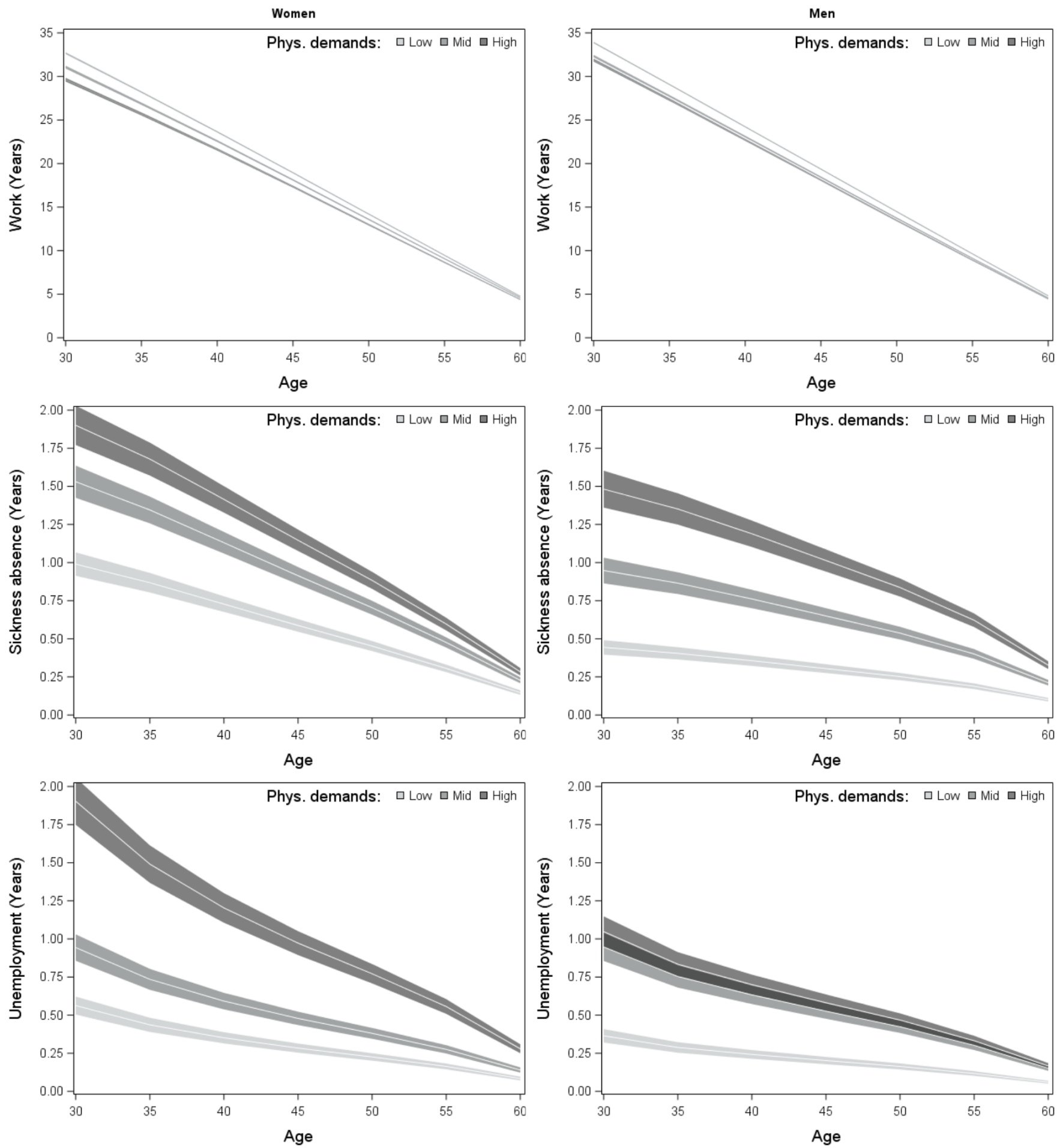

Figure 2 The working life expectancy (WLE) and expected time of unemployment and sickness absence for 30-60 years old among individuals with low, medium, and high physical work demands, stratified by sex. First row: number of years expected to be working, second row: number of years expected to be on sickness absence, and third row: number of years expected to be unemployed.

work demands. As compared with people with low physical work demands, WLE at the age of 50 years, 40 years and 30 years was significantly reduced among men and women with high physical work demands by $1.2-3.1$ years and $1.0-2.0$ years, respectively. In both sexes, high-exposed persons were expected to have significantly more time on sickness absence, unemployment and disability pension than the low-exposed. Among men, the largest reduction in WLE was due to sickness absence, followed by unemployment. While among women, the expected time of unemployment was higher than the expected time of sickness absence. Overall, women were expected to have more time of unemployment than men and the difference between the high-exposed and low-exposed groups was larger for women than men. Although the difference in the expected years of sickness absence between the high-exposed and low-exposed groups was similar in both sexes, irrespective of physical work demands, 
Table 2 The expected time in different states by sex, age and physical work demands group

\begin{tabular}{|c|c|c|c|c|c|c|c|}
\hline \multirow[b]{2}{*}{ Status } & \multirow{2}{*}{$\begin{array}{l}\text { Physical work } \\
\text { demands }\end{array}$} & Work & Sick & Unemployed & Temporary out & Disability pension & Death \\
\hline & & Years $(\mathrm{Cl})$ & Years (Cl) & Years (CI) & Years (CI) & Years (Cl) & Years (CI) \\
\hline \multicolumn{8}{|l|}{ Women } \\
\hline \multirow[t]{3}{*}{30 years } & Low & 32.67 (32.56 to 32.78 ) & 0.99 (0.91 to 1.07$)$ & 0.56 (0.50 to 0.62$)$ & 0.46 (0.43 to 0.49$)$ & 0.29 (0.25 to 0.33$)$ & 0.04 (0.03 to 0.05$)$ \\
\hline & Mid & 31.07 (30.91 to 31.23 ) & 1.53 (1.42 to 1.64$)$ & 0.94 (0.86 to 1.03$)$ & 0.53 (0.49 to 0.56$)$ & $0.88(0.80$ to 0.95$)$ & 0.06 (0.04 to 0.08$)$ \\
\hline & High & 29.62 (29.41 to 29.84$)$ & 1.90 (1.77 to 2.03$)$ & 1.90 (1.75 to 2.06$)$ & 0.54 (0.51 to 0.58$)$ & 0.93 (0.84 to 1.02$)$ & 0.07 (0.06 to 0.09 ) \\
\hline \multirow[t]{3}{*}{40 years } & Low & 23.64 (23.57 to 23.71$)$ & 0.73 (0.68 to 0.78$)$ & 0.35 (0.31 to 0.39$)$ & $0.06(0.05$ to 0.07$)$ & $0.19(0.16$ to 0.21$)$ & 0.03 (0.02 to 0.04$)$ \\
\hline & Mid & 22.58 (22.48 to 22.68 ) & 1.13 (1.06 to 1.20$)$ & 0.59 (0.54 to 0.65$)$ & 0.07 (0.06 to 0.08$)$ & $0.56(0.52$ to 0.61$)$ & 0.05 (0.04 to 0.06$)$ \\
\hline & High & 21.62 (21.49 to 21.76) & 1.41 (1.33 to 1.50$)$ & 1.20 (1.11 to 1.30$)$ & 0.07 (0.06 to 0.09 ) & $0.60(0.55$ to 0.66$)$ & 0.06 (0.05 to 0.08$)$ \\
\hline \multirow[t]{3}{*}{50 years } & Low & 14.20 (14.15 to 14.24$)$ & 0.45 (0.42 to 0.49$)$ & $0.23(0.20$ to 0.25$)$ & 0.01 (0.00 to 0.01$)$ & 0.09 (0.08 to 0.11$)$ & 0.02 (0.02 to 0.03$)$ \\
\hline & Mid & 13.58 (13.52 to 13.65$)$ & 0.70 (0.66 to 0.75$)$ & 0.38 (0.34 to 0.42$)$ & 0.01 (0.00 to 0.01$)$ & $0.28(0.25$ to 0.31$)$ & 0.03 (0.03 to 0.04$)$ \\
\hline & High & 12.98 (12.89 to 13.07$)$ & 0.88 (0.83 to 0.94$)$ & 0.77 (0.71 to 0.84$)$ & 0.01 (0.00 to 0.02 ) & $0.30(0.27$ to 0.33$)$ & 0.04 (0.03 to 0.05$)$ \\
\hline \multicolumn{8}{|l|}{ Men } \\
\hline \multirow[t]{3}{*}{30 years } & Low & 33.89 (33.82 to 33.97$)$ & 0.44 (0.40 to 0.49$)$ & $0.36(0.32$ to 0.41$)$ & 0.11 (0.10 to 0.13 ) & $0.09(0.07$ to 0.11$)$ & 0.09 (0.07 to 0.11$)$ \\
\hline & Mid & 32.34 (32.20 to 32.47$)$ & 0.95 (0.86 to 1.03$)$ & 0.95 (0.86 to 1.04$)$ & 0.15 (0.13 to 0.17$)$ & 0.40 (0.35 to 0.45$)$ & 0.15 (0.13 to 0.18$)$ \\
\hline & High & 31.87 (31.71 to 32.04 ) & $1.48(1.36$ to 1.60$)$ & 1.05 (0.95 to 1.15$)$ & $0.08(0.07$ to 0.10$)$ & 0.21 (0.17 to 0.26$)$ & 0.16 (0.14 to 0.19$)$ \\
\hline \multirow[t]{3}{*}{40 years } & Low & 24.22 (24.18 to 24.27 ) & 0.36 (0.32 to 0.39$)$ & $0.24(0.21$ to 0.27$)$ & 0.03 (0.02 to 0.04$)$ & $0.07(0.06$ to 0.09$)$ & 0.08 (0.06 to 0.09$)$ \\
\hline & Mid & 23.10 (23.00 to 23.19 ) & 0.76 (0.70 to 0.82 ) & 0.63 (0.57 to 0.69 ) & 0.04 (0.03 to 0.05$)$ & 0.32 (0.28 to 0.35$)$ & 0.13 (0.11 to 0.15$)$ \\
\hline & High & 22.72 (22.61 to 22.84$)$ & 1.19 (1.10 to 1.28$)$ & 0.70 (0.63 to 0.77$)$ & 0.02 (0.01 to 0.03$)$ & $0.17(0.13$ to 0.20$)$ & 0.14 (0.12 to 0.16$)$ \\
\hline \multirow[t]{3}{*}{50 years } & Low & 14.48 (14.45 to 14.51$)$ & 0.25 (0.23 to 0.28$)$ & $0.16(0.14$ to 0.18$)$ & 0.01 (0.00 to 0.01$)$ & 0.04 (0.03 to 0.05$)$ & 0.05 (0.04 to 0.06$)$ \\
\hline & Mid & 13.73 (13.67 to 13.79$)$ & 0.54 (0.50 to 0.58$)$ & 0.42 (0.38 to 0.46$)$ & 0.01 (0.01 to 0.02 ) & $0.20(0.17$ to 0.22$)$ & 0.09 (0.08 to 0.10$)$ \\
\hline & High & 13.46 (13.38 to 13.54$)$ & 0.84 (0.78 to 0.90$)$ & $0.47(0.42$ to 0.51$)$ & 0.01 (0.00 to 0.01$)$ & 0.11 (0.08 to 0.13$)$ & 0.09 (0.08 to 0.11$)$ \\
\hline
\end{tabular}

the expected years of sickness absence were higher for women than men. Though the study focuses on the contrast between the high-exposed and low-exposed, the study found no significant difference between the high-exposed and mid-exposed men with regard to the expected time in unemployment. This could be due to the high number of men with an unknown occupation in the mid-exposed group, some of whom may be misclassified by the JEM-though, still exposed because of their sex and age. ${ }^{28}$

\section{Comparison with previous studies}

Previous studies investigating the effect of physical work demands on labour market affiliation have typically quantified its impact on sickness absence and unemployment separately, without using a multistate framework or a life course perspective. Common estimates like ORs, relative risks or HRs can be difficult to interpret in a set-up containing multiple outcomes and recurrent transitions. In addition, relative estimates are typically difficult to convert to absolute numbers which show a direct impact. ${ }^{19}$

To our knowledge, this is the first study to explore the association between physical work demands and WLE. Therefore, the results of this study are not directly comparable with the findings of published studies. A recent Dutch study found that compared with highly educated workers, the WLE at age 30 years of low-educated men and women was reduced by 7.3 years and 9.9 years, respectively. ${ }^{25}$ Low-educated persons often lack vocational education. As compared with highly educated persons, they usually enter the workforce earlier and more frequently are occupied in jobs with physically demanding tasks. Compared with the Dutch study, our study may underestimate WLE at age 30 years between persons with high and low physical work demands. However, the two studies cannot be directly compared, due to different labour market and social systems, and because our study included only employed individuals while the Dutch study contains all individuals aged 30-66 years. Additionally, the Danish registers contain more accurate information on social payments by weekly updates, compared with the Dutch data which are based on monthly summaries.

Our results are in concordance with numerous previous studies on associations between physical workload and work disability (sickness absence and disability retirement), ${ }^{8} 101114$ as well with those reporting excess risk of work disability in

Table 3 Difference in working life expectancy and expected time in different states between high and low physical demands groups by sex and age

\begin{tabular}{|c|c|c|c|c|c|c|}
\hline & Work & Sick & Unemployed & Temporary out & Disability pension & Death \\
\hline & Years (Cl) & Years $(\mathrm{Cl})$ & Years (CI) & Years $(\mathrm{Cl})$ & Years $(\mathrm{Cl})$ & Years $(\mathrm{Cl})$ \\
\hline \multicolumn{7}{|l|}{ Women } \\
\hline 40 years & $-2.02(-2.32$ to -1.72$)$ & 0.68 (0.49 to 0.87 ) & 0.85 (0.65 to 1.05 ) & $0.01(-0.03$ to 0.05$)$ & 0.41 (0.29 to 0.53 ) & $0.03(-0.01$ to 0.07$)$ \\
\hline 50 years & $-1.22(-1.42$ to -1.02$)$ & 0.43 (0.30 to 0.56$)$ & 0.54 (0.40 to 0.68 ) & $0.00(-0.02$ to 0.02$)$ & 0.21 (0.14 to 0.28 ) & $0.02(-0.00$ to 0.04$)$ \\
\hline \multicolumn{7}{|l|}{ Men } \\
\hline 40 years & $-1.50(-1.74$ to -1.26$)$ & 0.83 (0.64 to 1.02 ) & 0.46 (0.31 to 0.61$)$ & $-0.01(-0.04$ to 0.02$)$ & $0.10(0.03$ to 0.17$)$ & $0.06(0.01$ to 0.11$)$ \\
\hline 50 years & $-1.02(-1.19$ to -0.85$)$ & 0.59 (0.46 to 0.72$)$ & 0.31 (0.21 to 0.41$)$ & $0.00(-0.01$ to 0.01$)$ & 0.07 (0.02 to 0.12$)$ & 0.04 (0.00 to 0.08$)$ \\
\hline
\end{tabular}


occupations involving physically demanding tasks. ${ }^{12}$ 32-37 The excess risk of preterm exit from paid employment via disability retirement in manual workers has been attributed to a range of factors including educational level and exposure to physical workload factors. ${ }^{833-36}$

Although in our study, both men and women were negatively affected by high physical work demands, we observed a clear difference between the sexes, with women being more negatively affected than men. There may be several explanations for this finding. First, women have a lower physical capacity by muscle strength than men, which increases the relative physical work demands in situations of similar absolute work demands (eg, lifting an object of $15 \mathrm{~kg}$ ). Considering the inherent loss of physical capacity with age in both men and women, women may reach a critical threshold at a younger age than the men, where the physical work is simply too demanding and withdrawal from the labour market is more likely.

The loss of working years for the high-exposed men and women was primary due to additional years of sickness absence and unemployment, but not by an equivalent increase of disability pension years. We suspect this finding is due to the disability pension reform of 1 January 2013, after which it became more difficult to be awarded a disability pension. ${ }^{38}$ Thus, as a consequence of this reform, an almost complete loss of workability is required to obtain disability pension. Furthermore, the process is usually longer than the 4-year follow-up period of the present study.

\section{Strengths and limitations}

The strengths of our study include the nationally representative register data with rich and complete information on social benefits, including sickness absence, disability retirement and unemployment from the DREAM register and assessment of physical work demands using sex-specific and age-specific JEM. The data made it possible to identify transitions between the different labour market states for each participant during the entire 4-year follow-up and assign time-varying exposure status. As the data on social benefits were register based and exposure was assessed by the validated JEM, there was neither selection bias nor recall bias. The large study sample and the detailed longitudinal data allowed to provide reliable estimates of WLE with very narrow CIs.

The study has limitations. First, the work state was defined as not receiving social benefits. Such periods could also suggest periods when living off, for example, savings, private pension schemes or the income of others. This definition of the work state is prone to misclassification bias and may cause an overestimation of the WLE. Second, the results of the study correspond to the high contrast division of the high-exposed and the low-exposed, and the study did not include a sensitivity analysis by a second classification. Third, the reduced workability for employees with high physical work demands is likely to be driven by additional causes not included in the study. For example, may low education levels and reduced job opportunities increase the time of unemployment, when businesses-characterised by high physical work demand-invest in automated production. Though some individuals may be able to change occupation, for example, through education, it might be difficult for others, for example, due to age, social, and economic reasons.

Fourth, among employees with long-term exposure to physically heavy work, there is evidence of a higher risk of chronic musculoskeletal disease than among employees with low physical work demands. Overall, as people grow older, the risk of having other chronic diseases, like for example, diabetes or degenerative joint diseases, increases. As chronic diseases increase the risk of sickness absence, and so on, ${ }^{39}$ it is very likely that the presence of chronic diseases is affecting the WLE results, for example, by increasing the bias of those with high physical work demands who remain employees at age 60 years. For this purpose, an alternative model with information on diagnosis-specific sickness absence states could have been informative, but due to Danish law, the reason for sickness absence is not registered, and individual diagnosis-specific information is very difficult to access for such a large sample.

Fifth, lifestyle factors like obesity and smoking are likely to affect the labour market affiliation, ${ }^{40}$ but the nature of their role as confounders and/or mediators of high physical work demands is unclear, and difficult to incorporate into a life course approach. For example, one might assume that high physical work demands lead to poor lifestyle and chronic disease, but poor lifestyles may also influence what job type a person has. ${ }^{26}$ The study uses a large register-based sample with no information available on individual lifestyle factors. Sixth, the study does not include other physical exposures like chemical and psychosocial exposures that are likely to influence the WLE results, for example, cause additional time of sickness absence, for certain occupations. Seventh, the WLE estimation is prognostic in nature, and is based on the theoretical assumption that by cumulating the behaviour of employees of different ages one can create a profile-specific behavioural pattern that represents employees of all ages. Such an assumption only holds for the purpose of predictions as long as the underlying conditions like the economic situation are comparable and relative stable. Likewise, our results are probably restricted to countries with social systems similar to Denmark. Finally, using a JEM-based exposure estimate may underestimate the influence of physical work demands on WLE, as it does not take into account the individual variability in exposure within the job groups and may cause nondifferential misclassification of exposure.

\section{CONCLUSION}

This study showed that high physical work demands are a marked risk factor for a shortened expected working life and increased years of sickness absence and unemployment. The effect for a 30 -year-old woman is 3.1 years less of working, 11 more months of sickness absence and 16 more months of unemployment. For a 30 -year-old man, the corresponding numbers are 2.0 years, 12 months and 8 months, respectively. The findings highlight the urgency of addressing problems related to physical work demands with regard to, for example, an increasing statutory retirement age, and it identifies groups for which it is advisable to place efforts, for example, young women with high physical work demands.

\section{Twitter Lars L Andersen @larslandersen}

Contributors JP wrote the original manuscript draft and designed the study, BBS conducted the analysis and contributed to writing the results section. IEHM constructed the job exposure matrices, contributed to writing the manuscript and the interpretation of the results. SS and LLA oversaw the study design and interpretation of the results and contributed to writing the final manuscript. The corresponding author had full access to all data and had final responsibility to submit for publication.

Funding The study was supported by NordForsk (grant number 76659) (JP, SS); and the Nordic Council of Ministers (grant number 101250) (JP, SS). The funders of the study had no role in study design, data collection, data analysis, data interpretation or writing of the report.

Competing interests None declared. 
Patient consent for publication Not required.

Ethics approval According to Danish law, research studies that use solely register data do not need approval from the National Committee on Health Research Ethics (Den Nationale Videnskabetiske Komité).

Provenance and peer review Not commissioned; externally peer reviewed.

Data availability statement Data may be obtained from a third party and are not publicly available. Data is available on the Researcher access at Statistics Denmark, see www.dst.dk/en/TilSalg/Forskningsservice.

Open access This is an open access article distributed in accordance with the Creative Commons Attribution Non Commercial (CC BY-NC 4.0) license, which permits others to distribute, remix, adapt, build upon this work non-commercially, and license their derivative works on different terms, provided the original work is properly cited, appropriate credit is given, any changes made indicated, and the use is non-commercial. See: http://creativecommons.org/licenses/by-nc/4.0/.

\section{ORCID iDs}

Jacob Pedersen http://orcid.org/0000-0003-4429-3485

Ida E H Madsen http://orcid.org/0000-0003-3635-3900

Lars L Andersen http://orcid.org/0000-0003-2777-8085

\section{REFERENCES}

1 Ilmarinen J. The ageing workforce--challenges for occupational health. Occup Med 2006;56:362-4

2 The Danish Agency for Labour Market and Recruitment (STAR). Folkepensionsalderen nu og fremover. Available: https://star.dk/ydelser/pension-og-efterloen/folkepensionog-foertidspension/folkepension/folkepensionsalderen-nu-og-fremover/ [Accessed 30 May 2019].

3 Lunenfeld B, Stratton P. The clinical consequences of an ageing world and preventive strategies. Best Pract Res Clin Obstet Gynaecol 2013;27:643-59.

4 World Health Organization. European health report 2018, 2019. Available: http:// www.euro.who.int/en/data-and-evidence/european-health-report/european-healthreport-2018 [Accessed 30 May 2019].

5 Schuring M, Robroek SJW, Otten FWJ, et al. The effect of ill health and socioeconomic status on labor force exit and re-employment: a prospective study with ten years follow-up in the Netherlands. Scand I Work Environ Health 2013;39:134-43.

6 Etman A, Burdorf A, Van der Cammen TJM, et al. Socio-demographic determinants of worsening in frailty among community-dwelling older people in 11 European countries. J Epidemiol Community Health 2012;66:1116-21.

7 Newton RU, Hakkinen K, Hakkinen A, et al. Mixed-methods resistance training increases power and strength of young and older men. Med Sci Sports Exerc 2002:34:1367-75.

8 Robroek SJW, Järvholm B, van der Beek AJ, et al. Influence of obesity and physical workload on disability benefits among construction workers followed up for 37 years. Occup Environ Med 2017;74:621-7.

9 Veiersted B, Knardahl S, Wærsted M. Mekaniske eksponeringer i arbeid som årsak til muskel- og skjelettplager. STAMI, 2017. Available: https://stami.no/ny-rapportmekaniske-eksponeringer-i-arbeid-som-arsak-til-muskel-og-skjelettplager/ [Accessed 20 Feb 2018]

10 Andersen LL, Fallentin N, Thorsen SV, et al. Physical workload and risk of longterm sickness absence in the general working population and among blue-collar workers: prospective cohort study with register follow-up. Occup Environ Med 2016:73:246-53.

11 Andersen LL, Thorsen SV, Flyvholm M-A, et al. Long-term sickness absence from combined factors related to physical work demands: prospective cohort study. Eur $J$ Public Health 2018;28:824-9.

12 Andersen LL, Villadsen E, Clausen T. Influence of physical and psychosocial working conditions for the risk of disability pension among healthy female eldercare workers: prospective cohort. Scand J Public Health:140349481983182 (Epub ahead of print February 28, 2019)

13 van den Berg TIJ, Elders LAM, de Zwart BCH, et al. The effects of work-related and individual factors on the work ability index: a systematic review. Occup Environ Med 2009:66:211-20.

14 Sterud T. Work-related mechanical risk factors for long-term sick leave: a prospective study of the general working population in Norway. Eur J Public Health 2014:24:111-6

15 Fridriksson JF, Tómasson K, Midtsundstad T, et al. Working environment and work retention. Nordisk Ministerråd, 2017. Available: http://urn.kb.se/resolve?urn=urn:nbn: se:norden:org:diva-5061 [Accessed 25 Apr 2019].
16 Willekens FJ. Multistate analysis: tables of working life. Environ Plan A 1980;12:563-88.

17 Smith SJ. Tables of working life: the increment-decrement model: bulletin 2135. Washington, DC: US Department of Labor, Bureau of Labor Statistics, 1982. www. fraser.stlouisfed.org/files/docs/publications/bls/bls_2135_1982.pdf

18 Nurminen M, Nurminen T. Multistate worklife expectancies. Scand I Work Environ Health 2005;31:169-78.

19 Pedersen J, Bjorner JB. Worklife expectancy in a cohort of Danish employees aged 55-65 years - comparing a multi-state Cox proportional hazard approach with conventional multi-state life tables. BMC Public Health 2017:17:879.

20 Dudel C, López Gómez MA, Benavides FG, et al. The length of working life in Spain: levels, recent trends, and the impact of the financial crisis. Eur J Popul 2018;34:769-91.

21 Loichinger E, Weber D. Trends in working life expectancy in Europe. J Aging Health 2016:28:1194-213.

22 Pedersen J, Thorsen SV, Schultz BB. Working Life Expectancy in Denmark [Den forventede arbejdslivslængde i Danmark. Et studie af arbejdsmiliøet og fastholdelse på arbejdsmarkedet]. National Research Centre for the Working Environment. Copenhagen. Available: http://nfa.dk/da/Forskning/Udgivelse?journalld=1f2d0foge273-4c03-9691-bb1b0a016fd1 [Accessed 31 Dec 2018].

23 de Wind A, van der Noordt M, Deeg DJH, et al. Working life expectancy in good and poor self-perceived health among Dutch workers aged $55-65$ years with a chronic disease over the period 1992-2016. Occup Environ Med 2018;75:792-7.

24 Sirén M, Viikari-Juntura E, Arokoski J, et al. Work participation and working life expectancy after a disabling shoulder lesion. Occup Environ Med 2019;76:363-9.

25 Robroek SJ, Nieboer D, Järvholm B, et al. Educational differences in duration of working life and loss of paid employment: working life expectancy in the Netherlands. Scand J Work Environ Health 2020;46:77-84.

26 Pedersen J, Thorsen SV, Andersen MF, et al. Impact of depressive symptoms on worklife expectancy: a longitudinal study on Danish employees. Occup Environ Med 2019;76:838-44.

27 Danmarks Statistiks. Arbejdsstyrken øget med 35.000 personer. Available: www.dst. $\mathrm{dk} / \mathrm{da} /$ Statistik/nyt/NytHtml?cid=27897 [Accessed 10 Aug 2019].

28 Madsen PK. How can it possibly fly?: the paradox of a dynamic labor market in a Scandinavian welfare state. CARMA research papers; 2. 38. CARMA: Aalborg Universitet, 2005. www.citeseerx.ist.psu.edu/viewdoc/download?doi=10.1.1.498. 5526\&rep=rep $1 \&$ type $=$ pdf

29 Hjollund NH, Larsen FB, Andersen JH. Register-based follow-up of social benefits and other transfer payments: accuracy and degree of completeness in a Danish interdepartmental administrative database compared with a population-based survey. Scand J Public Health 2007:35:497-502.

30 Madsen IEH, Gupta N, Budtz-Jørgensen E, et al. Physical work demands and psychosocial working conditions as predictors of musculoskeletal pain: a cohort study comparing self-reported and job exposure matrix measurements. Occup Environ Med 2018;75:752-8.

31 Beyersmann J, Putter H. A brief note on computing average state occupation times. Demogr Res 2014;30:1681-96.

32 Sundstrup E, Hansen Åse Marie, Mortensen EL, et al. Cumulative occupational mechanical exposures during working life and risk of sickness absence and disability pension: prospective cohort study. Scand I Work Environ Health 2017;43:415-25.

33 Haukenes I, Mykletun A, Knudsen AK, et al. Disability pension by occupational class-the impact of work-related factors: the Hordaland Health Study Cohort. BMC Public Health 2011:11:406.

34 Polvinen A, Laaksonen M, Gould R, et al. Socioeconomic differences in cause-specific disability retirement in Finland, 1988 to 2009. J Occup Environ Med 2016:58:840-5.

35 Leinonen T, Pietiläinen $\mathrm{O}$, Laaksonen $\mathrm{M}$, et al. Occupational social class and disability retirement among municipal employees--the contribution of health behaviors and working conditions. Scand J Work Environ Health 2011;37:464-72.

36 Solovieva S, Kontio T, Viikari-Juntura E. Occupation, physical workload factors, and disability retirement as a result of hip osteoarthritis in Finland, 2005-2013.J Rheumatol 2018;45:555-62.

37 Kadefors R, Nilsson K, Östergren P-O, et al. Social inequality in working life expectancy in Sweden. Z Gerontol Geriatr 2019;52:52-61.

38 Evaluation: reform of early retirement and flex jobs well underway but still challenges. Available: https://bm.dk/nyheder-presse/pressemeddelelser/2018/03/evalueringreform-af-foertidspension-og-fleksjob-godt-paa-vej-men-fortsat-udfordringer/ [Accessed 13 Nov 2019].

39 van den Berg T, Schuring M, Avendano M, et al. The impact of ill health on exit from paid employment in Europe among older workers. Occup Environ Med 2010;67:845-52

40 Virtanen $\mathrm{M}$, Ervasti J, Head J, et al. Lifestyle factors and risk of sickness absence from work: a multicohort study. Lancet Public Health 2018:3:e545-54. 